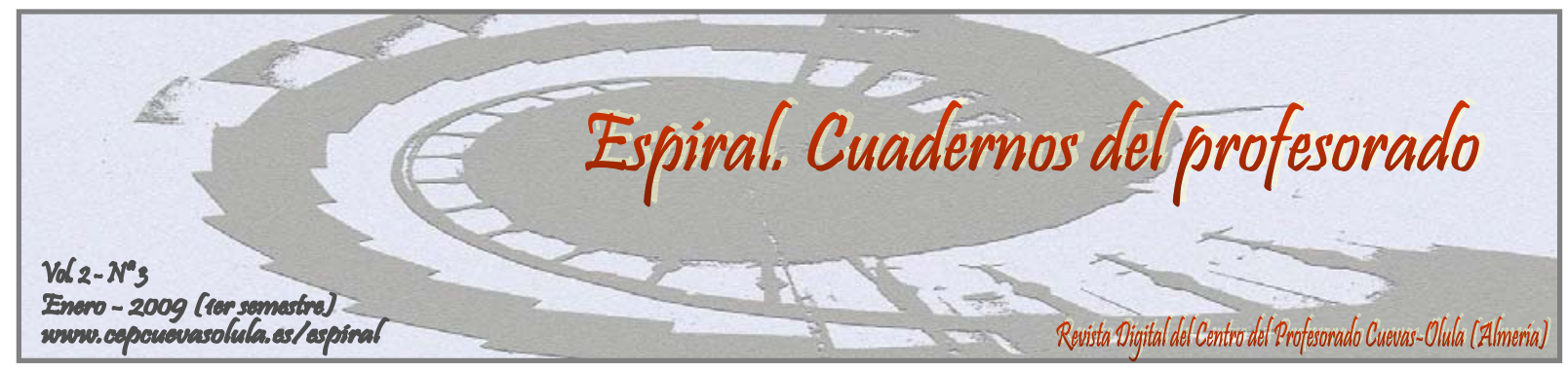

\title{
LOS TERREMOTOS DE 1863 EN LA COMARCA DEL LEVANTE ALMERIENSE
}

\author{
THE EARTHQUAKES OF 1863 IN THE REGION OF LEVANTE ALMERIENSE
}

\author{
Enrique Fernández Bolea
}

Escuela Oficial de Idiomas de Macael, Almería (España)

\begin{abstract}
RESUMEN: En el verano de 1863, entre el 10 de junio y finales de septiembre, el norte de la provincia de Almería sufrió el episodio sísmico más prolongado de su historia documentada. Pero fue especialmente la cuenca baja del Almanzora la que contempló cómo la tierra oscilaba de un modo casi permanente, sin dar tregua a unos habitantes que, asustados, acongojados por esa inusual dilatación de unas sacudidas muchas veces violentas e inesperadas, protagonizaron escenas de pavor, de desconcierto colectivo que pusieron a prueba la capacidad de reacción de las administraciones municipales y provincial. Aunque los daños materiales no fueron cuantiosos ni dibujaron un panorama de destrucción generalizada, las repercusiones sobre la población deberán ser calificadas de notables; y el miedo, la inseguridad, ese temor ante lo inesperado, provocaron el abandono de los núcleos urbanos y el éxodo de aquellos habitantes hacia su periferia, donde surgieron improvisados campamentos que los cobijaron durante más de tres meses. En definitiva, se desencadenó una situación social excepcional que respondió a un fenómeno natural no menos extraordinario.
\end{abstract}

Palabras clave: Terremotos, catástrofes naturales, Levante almeriense, Huércal-Overa, Cuevas del Almanzora, Vera.

ABSTRACT: In the summer of 1863, between June 10th and the end of September, the northern province of Almeria suffered the longest seismic episode of its documented History. But it was especially the lower Almanzora which included how the land ranged from an almost permanent basis, without giving some respire to people, frightened, bereaved by this unusual expansion of a violent shaking often unexpected, staged scenes of panic, puzzling group that tested the resilience of the municipal and provincial administrations. Although the damage was not extensive and drew a picture of widespread destruction, the impact on the population must be described as remarkable, and the fear that the unexpected insecurity, caused the abandonment of urban communities and the exodus of those people toward its periphery, where makeshift camps that emerged refuge for more than three months. In short, it sparked a social situation that responded to a unique natural phenomenon no less remarkable.

Key words: Earthquakes, natural disasters, Levante Almería, Huércal-Overa, Cuevas del Almanzora, Vera. 
Fernández Bolea, E. (2009). Los terremotos de 1863 en la comarca del levante almeriense. [en línea]. Espiral. Cuadernos del Profesorado, 2(3), 27-40. Disponible en: http://www.cepcuevasolula.es/espiral.

Enviar correspondencia a: enriquebolea@hotmail.com

\section{1.- UNA SUCESIÓN INUSUAL DE MOVIMIENTOS SÍSMICOS: FUENTES PARA UNA CRÓNICA.}

Transcurrían anodinos los días previos al verano de 1863 y el calor, puntual a su cita, amenazaba con instalarse en la cotidianidad de las gentes del Levante. Los pudientes preparaban ya una nueva temporada de baños en las playas de costumbre; los humildes, sin derecho a asueto, se entregaban al duro trabajo en la mina o al penoso esfuerzo que exigía el campo en días de canícula; otros, como era habitual, estaban a punto de partir hacia las tierras altas de Granada y Jaén para sacarse unos jornales en la siega del cereal, lo que entonces se conocía como "hacer las Andalucías”. Nadie podía imaginar en esos primeros días de junio que la normalidad se vería truncada por un fenómeno natural no demasiado extraño en esta comarca, aunque su posterior reiteración y extensión en le tiempo lo convirtiesen en excepcional. La mañana del 10 de ese mes se produjo un violento temblor de tierra que alarmó sobremanera a los habitantes de todo el Valle del Almanzora, desde Villaricos hasta Serón. Fue el primero -he aquí la excepcionalidad- de una serie de sacudidas que, casi a diario, se prolongaron hasta finales de septiembre. No hubo daños personales y los materiales, con ser notables en numerosos edificios, no supusieron una destrucción generalizada, sin embargo el efecto de aquellas insistentes trepidaciones sobre la población o, mejor dicho, sobre sus actitudes y comportamientos ante las fuerzas incontroladas de la naturaleza es lo que otorga sumo interés a este dilatado episodio. Las gentes, presas de inquietud, atemorizadas ante lo inesperado, protagonizaron escenas de desasosiego colectivo, de angustia y, en no pocas ocasiones, de irracionalidad como respuesta a esa naturaleza que había decidido mostrarse amenazadora e imprevisible.

La noticia de los insistentes terremotos que afectaban a las comarcas septentrionales de la provincia de Almería arribó a la Corte a través de los constantes telegramas que emitía su gobernador, quien se nutría, a su vez, del flujo informativo que habían abierto los distintos alcaldes de las localidades perjudicadas mediante el uso más o menos periódico del telégrafo y el correo. La prolongación en el tiempo de las sacudidas y el estado de pavor en que se hallaban sumidos los habitantes de aquellos pueblos llevó al Gobierno a interesarse por tan anómala situación, y decidió enviar a un especialista para que tratase de indagar sobre las causas y consecuencias de aquel episodio sísmico. De este modo, una Real Orden de 25 de julio, expedida por el Ministerio de Fomento, encargaba a Casiano del Prado ${ }^{1}$, ingeniero de Minas y -como gustaba titularse- "individuo de la Sociedad Meteorológica de Francia", el estudio de aquellos terremotos y de las circunstancias que los acompañaron:

“[...] expondré las observaciones que tuve lugar de hacer, no sólo por lo referente a la parte científica, sino también a los medios de disminuir los desastres que causan muchas veces, como en aquella parte del reino se vio

\footnotetext{
${ }^{1}$ Nació en Santiago de Compostela el 13 de agosto de 1797. En su juventud sufrió los rigores de la Inquisición, siendo encarcelado por esta caduca institución durante quince días. En 1821 llega a Madrid para concluir los estudios de arquitectura, y fue entonces cuando, por influencia y consejo de Jacobo María Parga, se decide finalmente por la mineralogía. Se matriculó en la Casa de la Dirección General de Minas y, tras pasar por diversos exámenes públicos, fue nombrado alumno pensionado en 1829 con un sueldo anual de 4.400 reales. Hasta 1834 pasó por las minas y fábricas de Almadén, Linares, Adra y Río Tinto, donde estudió el laboreo de minas e hizo sus prácticas levantando planos y hornos. Nombrado en 1834 ingeniero de minas de tercera clase, desempeñó el cargo de director principal de las de Almadén y Río Tinto y, a partir de 1848, ocuparía el puesto de vocal en la Comisión del Mapa Geológico. Esmerado profesional, produjo abundante literatura en forma de estudios y memorias sobre minería, obteniendo por todo ello numerosos reconocimientos. Su fallecimiento se produjo en 1866. Los datos precedentes proceden de ARCINIEGA, J.: “Biografía”, en Revista Minera, tomo XVII, 1866, pp. 449-453.
} 
antes de ahora, de lo cual presentaré también una breve reseña histórica" ${ }^{2}$.

Porque hemos tenido la gran fortuna de que el ingeniero plasmase pormenorizadamente lo que vio y escuchó durante las jornadas de su visita, aunando al reflejo de las vicisitudes cotidianas sus propias apreciaciones científicas; todo ello adquirió forma de informe que se publicó con el título de "Los terremotos en la provincia de Almería”3. Ahora bien, el técnico no llegaría a Huércal-Overa, su primer destino en la comarca, hasta el día 6 de agosto, por lo que su fuente principal de información para los casi dos meses previos en que venían sucediéndose los temblores fueron los partes -mencionados más arriba- emitidos por los alcaldes y dirigidos al Gobierno de la provincia. Este suculento aporte documental para nuestro trabajo se complementará con las escasas referencias bibliográficas referidas al telúrico acontecimiento, como las vivencias en primera persona del historiador huercalense García Asensio que con posterioridad plasmará en su Historia de Huércal-Overa, y será ampliamente enriquecido con las numerosas informaciones vertidas por la prensa nacional del momento que, en algunos casos, reprodujo con cierta fruición y exacerbado dramatismo las crónicas enviadas por los corresponsales destacados en cada una de las localidades damnificadas. Otras fuentes bibliográficas y periodísticas han citado aquellos hechos sin otorgarle la menor trascendencia; es el caso del erudito almeriense Castro Guisasola ${ }^{4}$,

\footnotetext{
${ }^{2}$ PRADO, Casiano del: "Los terremotos de la provincia de Almería, por D. Casiano del Prado, individuo de la Sociedad Meteorológica de Francia, etc. (I)”, en Revista Minera, tomo XIV, 1863, p. 549.

${ }^{3}$ Esta memoria o informe disfrutó de amplia difusión en su día, ya que, al margen de su reproducción en la Revista Minera, se incluyó también en las páginas de Galicia: revista universal de este reino, números 13 al 19. Ya en la provincia de Almería, una parte del informe fue recogida y transcrita por OCHOTORENA, Fernando: La vida de una ciudad. Almería. Siglo XIX (1850-1899), Almería, Librería-Editorial Cajal, 1977, pp. 65-83. Expuestos de un modo más parco, Antonio MOLINA SÁNCHEZ rescata del informe de Casiano del Prado algunos datos más bien curiosos y anecdóticos en El libro de Cuevas del Almanzora hace un siglo, Almería, Ayuntamiento de Cuevas del Almanzora, 1990, pp. 186-187.

${ }^{4}$ CASTRO GUISASOLA, F.: "Terremotos en la provincia de Almería”, en La Independencia, publicado por entregas entre el 6 de abril y el 14 de junio de 1932.
}

quien en un recorrido histórico por los terremotos que han afectado a Almería y su provincia aludió a los de 1863 como la culminación de un período de enorme actividad sísmica que se inició en 1858 y tuvo significativos repuntes en 1860 y 1861, si bien no les concede la importancia que, desde una perspectiva social y psicológica, tuvieron para los habitantes del septentrión almeriense.

Por último, no he dejado de lado los datos que brotan de la documentación institucional generada por los Ayuntamientos de Cuevas, Huércal y Vera, de los que se desprende la tremenda preocupación de unas autoridades que, en determinados momentos, se vieron desbordadas por ese ambiente de miedo colectivo que se apoderó de sus ciudadanos ante los incesantes temblores.

\section{2.- HUÉRCAL-OVERA: LA LOCALIDAD MÁS AFECTADA.}

El primer parte que llegó al Gobierno provincial tenía fecha del 12 de junio y procedía de HuércalOvera $^{5}$. En él se podía leer que a las once y cuarto de la mañana del día 10 se sintió un terremoto muy violento que alarmó sobremanera a la población. Según testimonios contemporáneos, el fenómeno se inició con un intenso ruido subterráneo al que sucedieron de inmediato unas bruscas oscilaciones del terreno, infligiendo tal temor entre sus habitantes que huyeron despavoridos hasta campo abierto. Nuevos temblores se repetirían ese mismo día a la una, cuatro y cinco de la tarde, así como a las doce de la noche. Y mientras la tierra no dejaba de estremecerse, esa misma tarde el vecindario, alentado por las autoridades, se afanaba en levantar chozas, barracas e improvisadas tiendas de campaña en algunas plazas anchas y en los alrededores de la población, alejados de cualquier construcción que supusiese un riesgo en caso de derrumbe. A propagar este estado de inquietud colectiva contribuiría el conocimiento de algunos de aquellos convecinos de saberse sobre terrenos volcánicos, así como "la creencia popular de que salido del seno del mar [el territorio sobre el que se asienta el pueblo] tiene que volver a él" ${ }^{\text {. }}$. Al final de aquel día aciago los huercalenses habían dejado desierta su población, de la que escaparon con todo lo necesario para subsistir y sin

\footnotetext{
${ }^{5}$ PRADO, Casiano del: “Op. cit.”, p. 551.

6 “Terremotos en la provincia de Almería”, en Escenas Contemporáneas, Tomo I, Madrid, Imprenta del Colegio de Sordo Mudos y Ciegos, 1863, p. 385.
} 
intención de volverla a pisar mientras durase el fenómeno.

Este primer terremoto de consideración y las réplicas que lo sucedieron no provocaron daños personales en el núcleo urbano, a pesar de haberse derrumbado algunas habitaciones y una esquina de la iglesia del Santo Sepulcro. Junto a estos desperfectos, sobresalen los que soportó la iglesia parroquial,

"que parece quedó muy resentida, observándose, además de varias grietas en la bóveda y paredes, que se ha torcido la parte superior del cimborrio de la media naranja con su remate y cruz hacia la Sur, lo que indica que las oscilaciones fueron en aquel sentido" ${ }^{\text {. }}$.

Donde a punto estuvo de asomar la desgracia fue en las afueras de la villa, en la rambla de las Moreras, a la altura del cerro del Castillo. Allí se encontraban lavando, como era costumbre, unas mujeres cuando se sintió el primer temblor de tierra, cuya intensidad produjo un desprendimiento de piedras y tierra que desde ambas laderas se precipitó hasta el lugar donde se hallaban las lavanderas, alcanzando a una de ellas que, si bien salvó la vida de milagro, sufrió la fractura de un brazo por dos partes ${ }^{8}$.

Desde los primeros días se organizaron rogativas implorando la clemencia de la divinidad, acto que ante la prolongación de los sacudimientos se reiteró en numerosas ocasiones a lo largo de aquel dilatado período. Sin embargo, la que se celebró el 11 de junio contó con una mayor solemnidad al procesionar la Virgen del Río desde la ermita que la acogía, a tres cuartos de hora del núcleo, hasta hacer su entrada en la localidad ${ }^{9}$.

Tampoco faltó quien quiso ver, a lo largo de aquellos tres meses de actividad sísmica, una cierta regularidad en la reiteración de los movimientos:

"Notóse allí desde un principio el raro fenómeno de que los más fuertes temblores se sintieron periódicamente, a las mismas horas, en los días que van de trastorno; siendo particularmente privilegiadas las de una, cuatro, ocho y

\footnotetext{
${ }^{7}$ La Esperanza, Año XIX, no ${ }^{\circ}$.732, 17 de junio de 1863, p. 3.

${ }^{8}$ Ibidem.

${ }^{9}$ Ibidem.
}

once de la mañana, así como las cuatro de la tarde ${ }^{\# 10}$.

Nuestro ingeniero Del Prado, recogiendo la información vertida por el alcalde en su segundo parte dirigido al gobernador, menciona que, sin haber cesado los movimientos desde que se iniciase el episodio, sólo el 18 de junio, de las ocho a las once de la mañana, se contabilizaron doce sacudidas, "cuatro de ellas espantosas". Precisamente en ese día tiene lugar un hecho que nos ofrece datos sobre la manera en que las autoridades y los personajes más influyentes de la sociedad huercalense -también en otras localidades se funcionó del mismo modoorganizaron la vigilancia y seguridad de la población a lo largo de aquellas jornadas de excepción: se trataba de unas brigadas que recorrían las calles y plazas de la deshabitada localidad, notificando cualquier incidencia o anomalía a la autoridad. Pues bien, a las dos de la madrugada el cirujano Patricio Martínez daría parte al alcalde, Vicente Ballesta Mena, de que en una de las casas principales de la localidad se habían oído golpes frecuentes, lo que hacía presumir que la ocupaban algunos individuos con el fin de robarla. Después de las pertinentes comprobaciones, en las que el alcalde dio muestras de sobrado valor encaramándose hasta el tejado de aquella casa de tres plantas "en medio de los frecuentes terremotos que en aquellas horas se sentían", se cercioraron de que los ruidos habían sido producidos "por un madero del último techo que se había caído y por los desprendimientos de otros cuatro o seis que estaban quebrados y amenazaban ruina" ${ }^{\text {"11. }}$.

Aquel 18 de junio fue el preámbulo de lo que estaba a punto de acontecer al día siguiente cuando, tras unos veinte temblores que formaron una oscilación casi ininterrumpida, se produjo una fuerte sacudida sobre las ocho de la mañana, "y esta circunstancia con el aspecto que presentaba la naturaleza, triste y amenazador, $e$ inmensas nubes de polvo, hacían temer a cada momento una erupción volcánica" ${ }^{\text {"12 }}$. Esa hipotética amenaza nunca se cumplió, pero el movimiento sísmico hizo vibrar bruscamente las casas y torres de la población, tejados enteros se vinieron a tierra, se abrieron enormes grietas en

\footnotetext{
${ }^{10}$ El Clamor Público, $2^{\mathrm{a}}$ Época, $\mathrm{n}^{\mathrm{o}} 875,27$ de junio de 1863, p. 2.

${ }^{11}$ La Esperanza, Año XIX, no ${ }^{\circ}$ 5.745, 2 de julio de 1863, p. 2.

12 “Terremotos en la provincia de Almería”, p. 385.
} 
los edificios más sólidos, la iglesia parroquial sufrió considerables desperfectos y la torre del Santo Sepulcro se separó del resto del edificio. De alarmantes podrían calificarse los desperfectos causados sobre el edificio que recientemente había sido construido para albergar el juzgado y el ayuntamiento, donde también se había ubicado la cárcel pública; tan resentido quedó el inmueble tras los temblores del 19 que la autoridad se vio obligada a trasladar a los presos a una barraca habilitada en las afueras de la población. Sobre este particular se recogen algunos testimonios impactantes, como el relatado por el corresponsal de La Esperanza quien alude a los desesperados gritos de los presos pidiendo "que los sacaran de aquella mansión aunque los cargaran con cadenas"; el alcalde se apiadó de aquellos desgraciados y dispuso que se levantara la tienda de campaña que luego los albergó: "En seguida sacó a todos los presos y los colocó en ella: dicen que era un espectáculo ver a aquellos hombres, en cuyos rostros estaba retratada la consternación, preferir que los guardasen con grillos por salir de un edificio que amenazaba ruina" $"$.

Quiso la casualidad que un número considerable de los vecinos hubiesen abandonado las zonas de acampada y se hallasen visitando sus domicilios -acto convertido en rutinario con el fin de velar por sus propiedades y enserescuando los sorprendió el violento terremoto del 19. El miedo se materializó en un ensordecedor griterío que sembraba el desconcierto a medida que se propagaba por la población; y en medio de aquella turbación colectiva, el caos se manifestaba en forma de carreras incesantes, pues cada uno corría en busca de los suyos sin reparar en el riesgo al que se exponía. Fueron momentos de espantosa confusión, una situación de agitación generalizada ante la que las autoridades se tuvieron que emplear a fondo para que no adquiriese proporciones más graves. En la consecución de un poco de orden en medio de aquella excitación destacaron el alcalde Vicente Ballesta Mena, el concejal Juan Bautista López, el cura párroco Salvador Valera Parra y sus capellanes, el juez de paz Benigno Ascasio, el promotor fiscal Evaristo Martí, el registrador de la propiedad Federico Fajardo y el médico

\footnotetext{
${ }^{13}$ La Esperanza, Año XIX, no 5.741, 27 de junio de 1863, p. 2.
}

forense Nicolás Ruso Martínez ${ }^{14}$. Todos ellos, asistidos por la dotación de la Guardia Civil, contribuyeron de nuevo a la salida ordenada de la población hacia los asentamientos temporales, obligando igualmente al cierre de las oficinas y servicios que aún funcionaban dentro del pueblo. También procedieron a la evacuación de los enfermos, que "salieron en carros o en colchones y sillas que todos se prestaban a conducir"15. Casiano del Prado alude a otros fenómenos curiosos que tuvieron en aquel temblor su origen o desencadenamiento: "Las aguas de una fuente -no dice cuál- se enturbiaron por espacio de seis horas, notándose más de dos terceras partes de aumento en el manantial desde aquel día. Junto al río Almanzora desapareció otra fuente -tampoco especifica su nombre-, saliendo después de quince días a 40 metros de distancia; y las plantas que con sus aguas se habían regado se secaron. Algunos molinos harineros pararon un corto tiempo por el retroceso de las aguas que les daban movimiento. A impulsos del temblor hubo carruajes que rodaron de suyo un corto trecho $[\ldots]$...16.

El corresponsal del periódico madrileño $L a$ Esperanza, testigo de unos hechos que relató con riqueza de matices y profusión de elementos anecdóticos, señalará igualmente la reiteración e ímpetu de las oscilaciones: "El mismo día refiriéndose al 19- fue un continuo terremoto: constantemente se oía un rumor sordo; la tierra tenía un movimiento constante, y parecía que pisábamos sobre un volcán; esto acobardaba más que las oscilaciones porque se temía una erupción volcánica"17. De nuevo afloraba esa creencia tan afianzada de que un cataclismo acabaría con la población, lo que contribuía a alimentar -aún más si cabe- ese estado de pánico que angustiaba a aquellos habitantes. Al día siguiente -según la misma fuente- se contabilizaron hasta doce movimientos; uno de ellos, que tuvo lugar a las cinco de la mañana, muy fuerte. Sin embargo, el 21 es considerado por el relator como un día de calma, puesto que sólo se percibieron dos o tres de madrugada y otros tantos por la tarde. Es significativa la calificación de tranquila para una jornada en la

\footnotetext{
${ }^{14}$ El Clamor Público, $2^{\text {a }}$ Época, $n^{\circ} 875,27$ de junio de 1863, p. 2.

${ }^{15}$ Ibidem.

${ }^{16}$ PRADO, Casiano del: Op. cit., 1863, p. 554.

${ }^{17}$ La Esperanza, Año XIX, $\mathrm{n}^{\circ} 5.741,27$ de junio de 1863, p. 3.
} 
que se percibieron unas seis sacudidas, resultando suficientemente elocuente de la adaptación de aquellas habituadas gentes a una actividad sísmica completamente anómala. Tanto es así que el más leve síntoma de relajación en el régimen de temblores era correspondido con un rebrote de la cotidianidad, aunque, eso sí, con la prudencia y la prevención que las circunstancias exigían: el día 22 se celebraba el tradicional mercado semanal en las afueras de la población; varias rogativas alrededor de ella se sucedían a lo largo de una misma jornada; los templos estaban cerrados y sólo se celebraba misa en la ermita de San Juan porque es la que se encontraba en mejor estado y estaba ubicada en una calle bastante ancha con edificios muy bajos, ambas peculiaridades facilitaría, en caso de terremoto, la huida segura de una feligresía que, desconfiada, hacía días que oía el oficio religioso desde el exterior. Fueron muchas las ocasiones en que estuvo en riesgo la vida de personas, produciéndose desenlaces milagrosos:

"El 19, a poco de sentirse el terremoto grande, llegó aquí uno que venía por la rambla del Saltador, cuando la conmoción, y me dijo creyó perecer. Al estremecimiento, cayeron por ambas riberas una porción de terreras; el mulo que montaba se espantó y cayó, quedando envueltos ambos entre una nube de polvo. En el río, en frente de Los Orives, se hallaban dos niños a la sombra de una terrera de más de cuarenta varas de alta, apacentando un rebaño de doscientas cabras; con el temblor se desplomó la terrera sobre el sitio donde se hallaba el rebaño y los pastores; instintivamente huyeron sin sufrir percance alguno [...]. Hallábase en el campo en un pequeño cortijo una familia poco acomodada, y al dar una sacudida se cayeron hacia fuera las dos paredes del cortijo que no sostenían las maderas; quedaron intactas en las que se apoyaban, saliendo ilesa aquella familia casi milagrosamente" ${ }^{\prime 18}$.

De cómo los acontecimientos habían mutado el modo de reaccionar de la gente nos convence el aplomo, la serenidad de nuestro corresponsal en el mismo momento de relatar su crónica, confirmando a su vez la resignación de todo un pueblo ante lo que se le había venido encima:
"Acaba de sentirse otro terremoto muy fuerte al concluir la última letra; lo anuncio sin levantar la pluma del papel, pues como estamos acostumbrados ya nos asustan poco: al producirse el fenómeno miramos a los edificios y a los montes, y los vemos a unos y a otros oscilar; en seguida dirigimos la vista hacia las ramblas, $y$ vemos en casi todas una nube de polvo, lo cual indica un desprendimiento; parece imposible que presenciemos con tranquilidad esta escena. Cuando sentí esta última sacudida, se movió la mesa en que escribo, y parecía que me faltaba la tierra de los pies; me encontraba y me encuentro rodeado de gente, y sin embargo no ha salido de entre nosotros ni un grito de espanto [...]" ${ }^{\text {"19. }}$.

"Seguimos en el campo porque siguen los terremotos", decía el corresponsal de $L a$ Esperanza el 22 de junio. Y aquella decisión estaba más que justificada porque en las doce jornadas que habían transcurrido desde el comienzo de los mismos hubo quien contabilizó hasta doscientas oscilaciones de mayor o menor intensidad. Ahora bien, vino a acrecentar el pavor y el desconcierto que sufrían aquellas gentes la terrible tempestad que se desató la tarde del 29 de junio: acompañada de abundante aparato eléctrico, una ligera lluvia se prolongó hasta pasada la medianoche. A pesar de la precipitación persistente, los habitantes de aquellos campamentos improvisados permanecieron inicialmente en sus tiendas $\mathrm{y}$ barracas. Sólo cuando las endebles habitaciones estuvieron caladas por completo decidieron abandonarlas y trasladarse a la población en busca de cobijo,

"mas cuando apenas habían llegado a sus casas, un terremoto bastante fuerte les hizo lanzarse precipitadamente a la calle, en medio de la oscuridad, llenos de espanto y consternación, corriendo despavoridos a las afueras del pueblo, prefiriendo sufrir la tormenta en medio del campo a morir aplastados bajo las ruinas de las casas que, quebrantadas con las anteriores oscilaciones, comenzaban a desplomarse a impulsos de

\footnotetext{
${ }^{19}$ Ibidem.
}

\footnotetext{
${ }^{18}$ Ibidem.
} 
la que acababa de experimentarse y de la constante lluvia" ${ }^{20}$.

$\mathrm{Y}$ es verdad que en aquel episodio se desprendió una gran parte de la cornisa de la iglesia parroquial; "por el lado de la puerta principal"; en la casa ocupada por la administración de Correos se desplomó una de las paredes y parecidas consecuencias sufrieron otros muchos edificios de la población.

Y mientras el infortunio se ensañaba con los desgraciados habitantes del Levante, el gobernador de la provincia intentaba adoptar medidas encaminadas a aminorar los efectos de la tragedia sobre una población desplazada y angustiada. Con este objetivo, considerando insuficiente lo que restaba en los presupuestos provinciales del llamado capítulo de calamidades, solicitó del Gobierno de la nación unos recursos económicos con los que, al menos, paliar los daños materiales. La insistencia de la máxima autoridad provincial se tradujo en un ingreso de 20.000 reales procedentes de los presupuestos generales del Estado que se distribuirían entre los damnificados. Para el adecuado reparto de este fondo se constituyó en cada pueblo una junta presidida por el alcalde e integrada, además, por el cura párroco, el diputado provincial del distrito y el juez de primera instancia ${ }^{21}$. Otra de las medidas arbitradas consistió en aumentar las dotaciones de la Guardia Civil de las principales poblaciones, ya que, en circunstancias como aquellas, a su habitual tarea de velar por la seguridad y el orden sumaban otras de carácter humanitario.

La primera semana de julio, lejos de cesar, se incrementó el número de temblores. Según las notas de Del Prado, entre el 1 y el 6 se sintieron 35 movimientos; uno de ellos, el del 2 de julio a las once y media de la noche tuvo una duración considerable y, como consecuencia, paralizó el curso de las aguas que accionaban algunos molinos, impulsó varias norias que se hallaban paradas y provocó el tañido de las campanas de la parroquial $^{22}$. El colofón, con suma de elementos desatados, se produjo la jornada del 7 cuando se sucedieron nueve terremotos de diverso rigor en medio de una tempestad con

\footnotetext{
${ }^{20}$ El Clamor Público, $2^{\mathrm{a}}$ Época, $\mathrm{n}^{\circ}$ 883, 7 de julio de 1863, p. 1.

${ }^{21}$ El Clamor Público, $2^{\mathrm{a}}$ Época, $\mathrm{n}^{\circ} 875,27$ de junio de 1863, p. 2, y “Terremotos en la provincia de Almería”, en Escenas Contemporáneas, 1863, p. 386.

${ }^{22}$ PRADO, Casiano del: Op. cit., 1863, p. 556.
}

vientos huracanados que derribó todas las barracas y tiendas de los campamentos ${ }^{23}$. La escasa actividad registrada durante el resto de julio hizo abrigar falsas esperanzas a los habitantes de Huércal sobre la posible conclusión de aquel período sísmico, y ello porque en 24 días solo tembló la tierra en 38 ocasiones y ninguna de las oscilaciones percibidas pudo calificarse de consideración ${ }^{24}$. Incluso hubo alguna que otra jornada en la que no se notó ni el más leve movimiento, algo completamente inusual desde que comenzase el episodio hacía un mes y medio. Fue tan sólo un espejismo, pues la madrugada del 6 de agosto se produjo -nos cuenta Del Prado- uno de los mayores que se sintieron con una duración de unos siete u ocho segundos. Se inauguraba de este modo una nueva etapa de incremento de actividad que culminó, recién iniciado el día 23 de agosto, con una sacudida que, precedida dos o tres segundos antes por un ruido "como el producido por el movimiento de dos carruajes", fue percibido hasta en Almería. Sobre este terremoto escribiría el alcalde de Huércal-Overa a Del Prado que se había manifestado "con un gran movimiento circular que no se había observado en los anteriores". Los contactos posteriores del primer edil con el ingeniero incidirán sobre la progresiva disminución de los fenómenos tanto en cantidad como en intensidad, diciéndole con fecha de 28 de septiembre:

"Sin embargo de que en esta se dejan sentir con frecuencia por muchos varios terremotos, son los más casi imperceptibles y que no llaman la atención, excepto el que se experimentó a las tres de la tarde del día 16 y otro a las nueve y media de la noche del 25 que despertaron a todo el vecindario",25.

A los casi tres meses de iniciarse este anómalo y excepcional episodio sísmico, los terremotos, aunque débiles, seguían sacudiendo el solar comarcano, lo que hacía sospechar a Del Prado que, sin poderlo asegurar con absoluta rotundidad, éstos se irían acabando paulatinamente.

Entre las curiosas consecuencias de tan dilatado período sísmico cabe destacar la muerte masiva de gatos en la localidad, y los que no perecieron quedaron flacos y extenuados. El

\footnotetext{
${ }^{23}$ Ibidem, p. 557.

${ }^{24}$ Ibidem.

${ }^{25}$ Ibidem, p. 561.
} 
mismo Del Prado anotará que en la casa donde vivía contó hasta nueve de estos animales y, al final, no sobrevivió ni uno. Atribuía este extraño efecto a algún gas particular que hubiese sido inhalado por los felinos ${ }^{26}$. También informaron al facultativo de que la mayor parte de las golondrinas habían desaparecido a principios de junio, cuando en años normales no emigraban hasta septiembre.

Testigo privilegiado de aquellas trágicas e imborrables jornadas fue el historiador local Enrique García Asensio, por entonces un niño al que impactaron sobremanera las dramáticas escenas, trufadas de miedo, lamento y desconcierto, que protagonizaron sus aterrorizados convecinos. Su testimonio vendrá a confirmar el relato de los hechos que acabamos de narrar y aportará alguna que otra vicisitud novedosa por haber pasado desapercibida hasta el momento. En efecto, el historiador admitirá la profunda impresión que causó en su conciencia infantil el horroroso incendio que, en aquellos días, se desencadenó en un gran depósito de fósforos, pues el siniestro espectáculo de "llamas y deletéreos humos" supuso el perfecto decorado para la calamidad que estaban viviendo los huercalenses:

“[...] a duras penas logró dominarse, porque su extinción completa tardó muchos días, como era natural dada la materia combustible, y solo se consiguió, cuando las circunstancias permitieron, aun con bastante peligro, transportar las humeantes cajas a las afueras $y$ enterrarlas ${ }^{27}$.

Y nos informa de los rudimentarios sistemas o artilugios que se pusieron en práctica con el fin de apreciar la actividad sísmica, habiéndole llamado la atención -quizás por su extremada sencillez- el consistente en un vaso con agua colocado sobre una estaca de madera clavada en la tierra, con el que se confirmaría que "las oscilaciones terrestres no cesaron casi ni un momento en dicho verano”. Pero lo que más nos impacta de las vivencias recogidas por García Asensio es el ambiente de respeto y

\footnotetext{
${ }^{26}$ PRADO, Casiano del: "Los terremotos de la provincia de Almería, por D. Casiano del Prado, individuo de la Sociedad Meteorológica de Francia, etc. (II)”, en Revista Minera, tomo XIV, 1863, p. 586.

${ }^{27}$ GARCÍA ASENSIO, Enrique: Historia de la villa de Huércal-Overa y su comarca, Murcia, Tipografía de José Antonio Jiménez, 1910, Tomo II, pp. 591-592.
}

consideración, "de franca y fraternal comunidad" que se apoderó de aquellos campamentos improvisados, y añadía:

“[...] predominaba generalmente la expansión y la alegría y buen humor, que en definitiva dio lugar a que se pasara un verano alegre y divertido que muchos sentían tuviera fin; y no se registró el más pequeño incidente desagradable $\mathrm{ni}$ se instruyó diligencia alguna judicial por hecho contrario a la ley y a la moral ${ }^{, 28}$.

Recuerda finalmente nuestro historiador que con el primer refrescamiento otoñal y el inicio de un período de lluvias, coincidentes ambas circunstancias climatológicas con una progresiva disminución de los temblores, "con el pesar de muchos, que ya se habían acostumbrado a aquella vida expansiva y bulliciosa, hubo de pensarse y decidirse la instalación de nuevo en el pueblo y así se efectuó, viniendo todo a la normalidad" ${ }^{29}$.

\section{3.- CUEVAS Y EL DISTRITO MINERO DE SIERRA ALMAGRERA.}

Esa interminable sucesión de terremotos leves salpicados por otros de mayor intensidad que hemos descrito para Huércal-Overa será percibida, con sutiles diferencias, en todas las localidades del Bajo Almanzora. Las repercusiones, con ser similares en muchos aspectos, presentarán en cada pueblo sus precisas particularidades. De este modo, el primer parte emitido por el alcalde de Cuevas, con fecha de 15 de junio, alertaba sobre la violenta sacudida del día 10 a las once y diez minutos de la mañana que inauguraba una insistente serie que, hasta la fecha del escrito, había acumulado 45 terremotos ${ }^{30}$. Como no podía ser de otra manera, también los habitantes de esta villa protagonizaron escenas de pavor y consternación; el desprendimiento de cornisas, el derrumbamiento de una esquina de la ermita del Santo Sepulcro y la caída de varias bolas de piedra que, a modo de almenas, culminaban la muralla del castillo fueron algunos de los efectos mas sobresalientes de aquel primer movimiento.

De relatar éstas y otras consecuencias de aquel amplio período de actividad sísmica se encargará -por motivos que conoceremos más adelante- el secretario del Ayuntamiento, erigido

\footnotetext{
${ }^{28}$ Ibidem, p. 592.

${ }^{29}$ Ibidem, p. 593.

${ }^{30}$ PRADO, Casiano del: “Op. cit.”, 1863, p. 552.
} 
de forma accidental en cronista de aquellos avatares $^{31}$. Será él quien mencione la apertura de grandes grietas en algunas calles de la localidad, destacando la que se produjo en las inmediaciones de la plaza de Isabel II, de unos 30 metros de larga por 10 centímetros de ancha. Casiano del Prado confirmará la existencia de esta enorme fractura como la mayor de las muchas que se abrieron por toda la comarca y anotará que de allí brotaban lo que, sin lugar a dudas, consideró emanaciones gaseosas. En los meses siguientes estas grietas acabarían por cerrarse $^{32}$. Otro efecto sobre la orografía de los alrededores fue el levantamiento de los terrenos en los cerros colindantes ${ }^{33}$.

La reiteración de las oscilaciones continuará contando el improvisado cronistaacrecentó el pánico entre los vecinos, quienes abandonarán sus hogares para trasladarse a esos parajes agrícolas de la periferia que ofrecían, por encontrarse en campo abierto, una mayor seguridad. Como ya ocurriese en la vecina Huércal, fue tal el contingente de población desplazado que nacieron, también aquí, esos destartalados campamentos de urgencia integrados por tiendas de campaña y barracas que servirían de cobijo temporal a aquella población asustada $^{34}$. Durante semanas soportarían la precariedad de los habitáculos y las malas condiciones higiénicas generadas por el hacinamiento, hasta el punto de temer la proliferación de enfermedades infecciosas que, como el cólera morbo, tanto se prodigaban por aquellos años. Esta calamitosa situación -dice el cronista- trascendió a los pueblos y ciudades cercanos, siendo el Ayuntamiento de Lorca, en comunicación de 2 de julio de 1863, el primero en ofrecer su auxilio a este vecindario.

Los días 18 y 19 de junio el primer edil cuevano generará dos nuevos partes que reflejarán un incremento en la frecuencia y entidad de unos temblores que iban a alcanzar su punto álgido a las nueve de la mañana del 19, momento en el que se produjo uno calificado por el alcalde como "extremadamente horroroso".

\footnotetext{
${ }^{31}$ Actas Capitulares, 13 de noviembre de 1863, Archivo Municipal de Cuevas del Almanzora (AMCA en nuevas citas), lib. 97.

${ }^{32}$ PRADO, Casiano del: “Op. cit.”, 1863, p. 586.

33 “Terremotos en la provincia de Almería”, en Escenas Contemporáneas, Madrid, Imprenta del Colegio de Sordo Mudos y de Ciegos, 1863, Tomo I, p. 385.

${ }^{34}$ La Concordia. Revista Moral, Política y Literaria, Año I, $n^{\circ} 13,2$ de agosto de 1863, p. 15.
}

Puede hablarse, pues, de una intensificación del fenómeno materializada en los 36 temblores que se percibieron desde el 20 hasta el 27 de junio. Diez se concentraron en ese primer día, cuatro de ellos tan fuertes que volvieron a vivirse escenas de histeria colectiva y a sembrar el desconcierto entre unas gentes que a la siguiente jornada, domingo, exigieron que la misa se celebrase al aire libre. Y como si de una confabulación de las fuerzas de la naturaleza se tratase, el 28 de junio los elementos mostraron su cara más amenazadora elevando al paroxismo el miedo de los cuevanos. Pero merece la pena dejar que sea la pluma del ingeniero Del Prado la que nos describa la perturbación de la atmósfera en aquella tarde en que tampoco la tierra dejó de estremecerse:

"A las seis de la tarde comenzaron a levantarse muchas nubes ligeras de diferentes puntos del horizonte que paulatinamente se fueron reuniendo, formando luego en la esfera otra nube espantosa al decir de las gentes, que por unas partes se presentaba negra y por otras arrebolada con la luz de aquellas horas, por todas iluminada con las chispas eléctricas que entre los estampidos del trueno se sucedían sin parar haciendo mil quiebros $y$ dirigiéndose del cielo a la tierra, y según creían ver algunos también de la tierra al cielo. Duró esta tempestad hasta las once y media de la noche; pero antes de concluir un viento huracanado que se levantó y los dos fuertes terremotos que hubo después de las nueve y media llevaron hasta el último extremo la consternación de aquella noche ${ }^{\text {} 35}$.

Nuestro particular cronista tampoco perderá la ocasión de narrar el estado de alarma vivido por los cuevanos la noche del 28, y su dramático relato confirmará ese tétrico y amenazador cuadro que el ingeniero acaba de proporcionarnos:

“Al oscurecer [...] se encapotó la
atmósfera presentándose
extraordinariamente cargada de
electricidad y sucediéndose sin cesar
relámpagos y truenos espantosos con
alguna lluvia que amenazaba ser en
cantidad considerable; vino esta nueva
calamidad a multiplicar los conflictos de

${ }^{35}$ PRADO, Casiano del: “Op. cit.”, 1863, p. 556. 
los hijos de Cuevas que veían las iras del Omnipotente sobre sus cabezas y bajo sus pies, y una parte de los que se hallaban fuera de la población volvieron a ella y con los pocos que en la misma quedaban se encaminaron al Templo [Ntra. Sra. de la Encarnación] a implorar las misericordias del cielo, y estando en aquel local una nueva y fuerte sacudida de la tierra (que se sintió de diez a once de aquella noche pavorosa) produjo el más completo espanto y aturdimiento, que no daba lugar a reflexionar a qué punto se encaminarían los amedrentados habitantes, que no se veían seguros ni en los campos ni en sus casas ni en el Templo del Dios vivo" ${ }^{\text {"36. }}$.

$\mathrm{Y}$ fue ese miedo incontenible el que, cuando tenían lugar las sacudidas más violentas, desencadenaban escenas de histeria colectiva en las que las gentes, en medio de un ensordecedor griterío, se abrazaban y se dirigían hasta la iglesia parroquial "despidiéndose como si aquella fuese

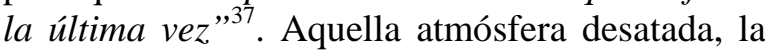
tempestad que en ocasiones precedió o acompañó al temblor de tierra, sumada a la circunstancia espacial de haberse dejado sentir en la zona próxima a las minas de Almagrera, hizo concebir las hipótesis más variopintas e inverosímiles, dominando la que atribuía "este fenómeno a causas eléctricas" $\$ 38$.

La actividad sísmica, lejos de desaparecer, se prolongó durante todo el estío de 1863. Según los partes de la alcaldía, entre el 1 y el 6 de julio se sintieron doce terremotos, siendo especialmente fuerte el del día 2 a las once y media de la noche. A partir de esta fecha se notará que en los momentos anteriores o posteriores a las oscilaciones, y a veces también durante las mismas, se escuchan "muchas detonaciones, que unas parecen proceder del centro de la tierra y otras que se verifican en el espacio". Recogía Casiano del Prado que algunos habían comparado el ruido de aquellos estruendos con el que provocan "los disparos de artillería de grueso calibre ${ }^{\text {39. }}$. Algún medio escrito de la época, tras

${ }^{36}$ Actas Capitulares, 13 de noviembre de 1863, AMCA, lib. 97.

${ }^{37}$ PRADO, Casiano del: “Op. cit.”, 1863, p. 562.

${ }^{38}$ La Concordia. Revista Moral, Política y Literaria, Año I, n ${ }^{\circ} 13,2$ de agosto de 1863, p. 15.

${ }^{39}$ PRADO, Casiano del: “Op. cit.”, 1863, pp. 556557. hacerse eco de estas fuertes detonaciones subterráneas, comentaba que el temor entre la población era grande porque cada vez que se producía un temblor algo fuerte "se veía salir una gran columna de polvo de un agujero que de antiguo hay hecho por la naturaleza en un monte que se halla como a una legua de distancia de esta villa"40.

Desde el día 8 hasta el final del mes de julio se contabilizaron unos 31 terremotos, aunque todos ellos se concentraron en 14 días, es decir transcurrieron algunas jornadas sin que los temblores afectaran a la población. El más notable de esta serie fue el que se produjo en la madrugada del 21, "fuerte y aterrador -dice el parte del alcalde-, añadiendo que a la media hora hubo otro más fuerte y así sucesivamente hasta cinco desde dicha hora hasta las dos de la tarde "41. La Guardia Civil, en uno de sus periódicos comunicados, anotará que, cuando se sintió el segundo, "la gente salía por las calles dando gritos y la población ofrecía un cuadro desconsolador”. Durante el mes de agosto debió de disminuir la frecuencia e intensidad de las sacudidas, ya que nuestro atento y meticuloso ingeniero recoge tan sólo un parte de la alcaldía de Cuevas en donde se alude a los cuatro terremotos sucedidos en la madrugada del 2 de agosto, uno de ellos de bastante consideración.

Entre los cambios físicos más notorios que ocasionó en Cuevas -y quizás en toda la comarca- aquel dilatado período de oscilaciones sísmicas, destacaría indudablemente la desaparición de la llamada laguna de la Albajaira, una acumulación natural de agua que, situada por debajo de la aldea de Los Orives, casi en el límite con el término de Huércal, ocupaba una superficie de unas cinco hectáreas donde hibernaban patos y otras aves acuáticas muy apetecidas por lo cazadores cuevanos. Como consecuencia de aquellos terremotos se abrieron grietas en su fondo y se secó de repente ${ }^{42}$.

Oscilaciones hubo hasta mediados de octubre cuando cesaron por completo, pero desde el ecuador del mes de agosto en adelante se fueron espaciando en el tiempo y perdiendo esa violencia con que se habían manifestado durante

${ }^{40}$ La Iberia, Año XI, no 2.781, 14 de julio de 1863, p. 2.

${ }^{41}$ PRADO, Casiano del: “Op. cit.”, 1863, p. 558.

${ }^{42}$ MOLINA SÁNCHEZ, Antonio: El libro de Cuevas del Almanzora hace un siglo, Almería, Ayuntamiento de Cuevas del Almanzora, 1990, p. 187. 
junio y julio. Habían transcurrido casi cuatro meses de confusión, de inseguridad permanente, de desazón; un período en exceso largo que paralizó la vida cotidiana de los cuevanos, sus actividades económicas y sociales, los ocios y divertimentos.

Ahora bien, como ya ocurriese con HuércalOvera, aquella tragedia colectiva motivó que el Gobierno de la provincia solicitara para Cuevas el auxilio económico de Madrid. Desde allí se enviaron algunas cantidades destinadas a socorrer y ocupar a las clases más necesitadas, surgiendo en ese momento del Ayuntamiento la idea de invertirlas en la construcción de una carretera que enlazase con la que conducía a la capital de la provincia. Iniciado el estudio del proyecto, Francisco Bravo Alarcón, alcalde accidental, vio la oportunidad de promover la defensa mediante muro de todo el frente del pago de Aljarilla (en la salida de la población hacia Vera), infraestructura que serviría además para proteger la nueva carretera y aumentar el número de fanegas de vega en el espacio de arenas entre el muro y el futuro camino. Pero no fueron pocas las dificultades que tuvo que afrontar el promotor Bravo, ya que la realización de aquel proyecto exigía el acuerdo de todos los terratenientes del pago sin excepción, pues de ellos, en reparto equitativo según la superficie poseída, saldrían los reales destinados a la financiación de la obra. La labor de convencimiento sobre cada uno de los hacendados y la necesidad de uniformar criterios en relación al beneficio de aquella construcción consumieron varias semanas de arduas negociaciones, culminando el proceso el 28 de julio con el compromiso de todos los propietarios para la ejecución del citado muro. Como consecuencia, las tierras de huerta de Aljarilla aumentaban en más de 25 nuevas hectáreas, lo que suponía un notable incremento de la riqueza agrícola de la villa ${ }^{43}$. Fueron estas las únicas consecuencias positivas de los terremotos de 1863.

Sobre los efectos de aquel episodio en el rico distrito minero de Sierra Almagrera, contamos con el testimonio del ingeniero Diego Laviña, por aquellos días director facultativo de algunas de sus explotaciones. A su colega Del Prado

\footnotetext{
${ }^{43}$ Actas Capitulares, 5 de julio y 10 de noviembre de 1863, AMCA, lib. 97. Estos datos fueron publicados por primera vez en FERNÁNDEZ BOLEA, Enrique: "Un día de San Diego hace 140 años", en Libro de Fiestas de San Diego, Cuevas del Almanzora, 2003.
}

proporcionará un conjunto de observaciones que permitirán reconstruir las repercusiones de los movimientos sísmicos en aquella parte del término municipal cuevano, confirmándose que la intensidad -al menos la percibida- y la incidencia de los mismos fue sensiblemente menor que en otros puntos de la comarca. Afirmará Laviña que la mañana del 10 de junio, en el momento de producirse el primero y uno de los más violentos, se encontraba realizando labores de inspección en la mina San Antonio, situada en el barranco Pinalvo; pues bien, no fue hasta las doce, al salir de la mina, cuando se le comunicó que una hora antes había habido un fuerte temblor de tierra, "lo cual me pareció broma en un principio -dice el facultativo- hasta que unánimemente me lo manifestaron todos los trabajadores de la superficie" "4. Ni él, ni las seis personas que lo acompañaban, ni siquiera los trabajadores que se encontraron por las distintas galerías y a diversa profundidad notaron nada, aunque sí observaron otros efectos que podrían haber tenido su origen en ese fenómeno natural. De este modo, recordaba Laviña que en la misma mina, a unas 225 varas de profundidad, había un sitio donde no se podía trabajar si no era con el auxilio de un ventilador de mano y a veces ni con ello; aquella jornada -sigue rememorando el ingeniero- dudaban de si podrían entrar en la excavación porque dos días antes estaba saturada de gas ácido carbónico y no se había ventilado; sin embargó, cuál fue su sorpresa cuando comprobaron que podían entrar y permanecer en aquel lugar durante bastante tiempo sin necesidad de ventilador. Esta renovación del aire sin necesidad de aplicar medios mecánicos fue achacada de inmediato a los efectos del terremoto.

En referencia al fuerte temblor del 19 de junio, los testimonios del ingeniero evidenciarán la manera tan dispar en que fue sentido por distintas personas que se encontraban en las inmediaciones de la mina Medio Mundo, en el barranco Francés de Almagrera. Laviña aseguró que, mientras él no percibió la más mínima oscilación, un sujeto que lo acompañaba en ese preciso instante lo alertó sobre el ruido de un temblor que acababa de sentir; y en seguida, un trabajador que se hallaba durmiendo en el cortijo de la mina, a diez metros de donde se encontraba el ingeniero, "salió despavorido, asegurando que se había sentido levantar sobre la cama más de

\footnotetext{
${ }^{44}$ PRADO, Casiano del: “Op. cit.”, 1863, p. 581.
} 
media vara". Ilustrativo de esa diferente percepción del fenómeno, y de la mayor o menor sensibilidad de las personas hacia estos terremotos, resulta la experiencia que relata el mismo Laviña por mediación de Del Prado:

"En lo alto de Sierra Almagrera se hallaban tres personas en una noche del mes de junio jugando al tresillo dentro de un cortijo; y una de ellas suelta de repente las cartas, diciendo: ¡terremoto!, mientras las otras dos nada habían sentido, y una de estas dos era el Sr. Laviña" ${ }^{\text {"5. }}$.

Cuando aconteció el terremoto del día 10, la máquina del desagüe del Jaroso se encontraba parada. A los dos o tres día reanudó su actividad y entonces se notó que para hacer descender las aguas hasta un nivel conocido por los maquinistas del establecimiento se invirtió de seis a ochos veces más tiempo del acostumbrado.

$\mathrm{Y}$ entre las curiosidades cosechadas por el ingeniero Laviña sobre los efectos de los terremotos cabría destacar la que hace referencia a la perforación de un pozo en el barranco Jaroso que, durante los temblores de junio, podría haber alcanzado las 200 varas de profundidad (unos 155 metros). Pues bien, durante uno de los terremotos más violentos los torneros de la superficie creyeron en riesgo sus vidas $y$ abandonaron el torno, pues aseguraban que habían visto precipitarse sobre sus cabezas los tirantes del porche; mientras tanto, los obreros que desempeñaban labores en el fondo del taladro no sintieron absolutamente nada ${ }^{46}$. En consecuencia, una de las conclusiones que se extraen de todas estas observaciones es que los temblores que se prodigaron durante aquel anómalo período sísmico apenas si fueron perceptibles en las profundidades de las minas, notándose mucho más amortiguados en la superficie de Almagrera que en el núcleo urbano de Cuevas y su periferia.

\section{4.- VERA: UNA CONFIRMACIÓN DE LOS EFECTOS.}

Una vez reflejada la secuenciación de los temblores, fuertes y leves, en las dos poblaciones precedentes, y anotados con bastante detenimiento los efectos sobre sus habitantes, proceder del mismo modo con la tercera población más castigada por aquella calamidad

\footnotetext{
${ }^{45}$ Ibidem, p. 585.

${ }^{46}$ Ibidem, p. 582.
}

sería reiterarnos en exceso, ya que la fuente principal de la que nos nutriríamos sería de nuevo el conjunto de partes emitidos por el alcalde de Vera, muy similar en la información transmitida a los que generaron las alcaldías de las otras dos localidades. Por ello me detendré en las particularidades que hayan quedado plasmadas en el informe de Casiano del Prado, aunque convenga ahora partir de los datos atesorados en otra fuente igualmente fiable: las actas capitulares.

Tras ese primer terremoto del 10 de junio, alarmante para los vecinos de toda la comarca, y la permanencia de las vibraciones en las jornadas sucesivas, los ayuntamientos adoptarán medidas encaminadas a prevenir futuros riesgos $\mathrm{y}$ garantizar la seguridad de sus ciudadanos. Vera ni iba a ser una excepción y a los pocos días, después de que la mayor parte de su población se hubiese trasladado a las barracas recién instaladas en las afueras del casco urbano, decidía organizar "para seguridad de las personas e intereses las rondas permanentes de tropa y paisanos", y exhortaba a los concejales

"para que cada uno por su parte contribuya a fin de que haya completa seguridad y que, en caso de hundimiento, todos estén prontos a socorrer a los desvalidos, y se acordó estar todos dispuestos a desempeñar el encargo que se les confiere [...]" "47.

En nueva sesión del Ayuntamiento de Vera, celebrada el 28 de junio, el alcalde manifestaba que, por efecto de los temblores de tierra, la cornisa del edificio del Ayuntamiento se encontraba arruinada y existía el riesgo de desprendimiento sobre los transeúntes; también algunos maderos que sustentaban la techumbre estaban partidos como consecuencia de las oscilaciones. Tampoco el pósito podía prescindir de una reparación urgente, por lo que se acordaba que tan pronto como cesasen los temblores - jno imaginaban lo que aún se prolongarían las sacudidas!- se procediese a la intervención en ambos edificios

"y si las partidas a cada uno de ellos no fueran bastante a cubrir el importe de las obras se haga uno de la de imprevistos hasta conseguir una completa solidez en los mismos, porque siendo de importancia y de necesidad suma ambos,

47 Actas capitulares, 14 de junio de 1863, Archivo Municipal de Vera (AMV en nuevas citas), lib. 185. 
sería lastimoso dejarlos abandonados, cuando tan recomendado está por la ley la conservación de los mismos"

En el caso del municipio de Vera, sabemos con exactitud -a través de la documentación generada por su máximo órgano de gobierno- la cantidad de dinero que se le asignó procedente de esa dotación extraordinaria del Estado destinada a auxiliar a los damnificados. Fueron 4.922 reales los que el Ayuntamiento, "a virtud de las órdenes recibidas del Sr. Gobernador Civil de esta provincia por consecuencia de los temblores", allegó a la Junta local con el fin de socorrer sobre todo a los enfermos y más desvalidos. El documento elaborado por el Gobierno local reunía de forma específica los listados, con nombres, apellidos y cantidades asignadas, de todos aquellos afectados que obtuvieron el beneficio de una ayuda económica, así como otras partidas con cargo a estas subvenciones estatales que abonaban los gastos ocasionados por la construcción de una barraca para los enfermos, evacuados del núcleo urbano por miedo a los probables derrumbamientos ${ }^{49}$.

Podrían llamar la atención algunos datos incluidos en los partes de Vera sobre la intensidad de los movimientos sísmicos, ya que hasta el momento hemos sabido por la información procedente de los otros municipios que los dos temblores más fuertes fueron los que tuvieron lugar los días 10 y 19 de junio. Sin embargo, testimoniados como especialmente violentos por los de esta localidad, e iguales o superiores a los antes mencionados, se sintieron los del 14 de julio y, aún más notable, el del 6 de agosto, que dieron lugar a escenas de terror incontenible, tal y como se refleja en un parte de la Guardia Civil coetáneo en el que se dice que "a cada paso se hallaban personas de rodillas en las calles haciendo oración"

Casiano del Prado refiere, entre los daños infligidos a edificios, el desplome parcial de la torre de un convento, sin especificar su nombre, si bien sería lógico pensar que pudiera tratarse del convento de los Padres Mínimos. Y como ya anotó para Huércal-Overa, el ingeniero incide en

\footnotetext{
${ }^{48}$ Actas capitulares, 28 de junio de 1863, AMV, lib. 185.

49 "Son cargo 4.922 reales 62 céntimos que el Ilustre Ayuntamiento puso a disposición de esta Junta para socorrer a los pobres desvalidos y enfermos durante los terremotos”, Expedientes, AMV, leg. 1.424.

${ }^{50}$ PRADO, Casiano del: “Op. cit.”, 1863, p. 562.
}

los efectos de este episodio sísmico en determinados animales que, como los gatos, sufrieron un anormal enflaquecimiento o, como las gallinas, perecieron de un modo masivo y extraño ${ }^{51}$.

En definitiva, Vera, como las otras localidades comarcanas, vio profundamente alterado el desarrollo de su actividad cotidiana, una perturbación que se tradujo en la paralización de los negocios, de los trabajos del campo y de otros servicios, oficios y formas de producción que tuvo como consecuencia el desabastecimiento, la escasez de comestibles, su encarecimiento y la poca o ninguna afluencia de vendedores a los mercados semanales. A todo ello se añadió el éxodo de los habitantes de aquellas villas y ciudades a campo abierto, conformándose asentamientos de población provisionales repletos de carencias higiénicas y sanitarias, caldo de cultivo propicio para todo tipo de enfermedades, incluidas las epidémicas. $\mathrm{Y}$ luego, el miedo ante los elementos, el desconcierto ante la incertidumbre, el desasosiego permanente $\mathrm{y}$ angustioso que produjo un período de actividad sísmica anormalmente duradero que sumió a la población en esa inquietante inseguridad que suele provocar lo inhabitual, lo desacostumbrado, lo desconocido.

Pero 1863 fue también un año de seísmos frecuentes y, a veces, brutales en todo el mundo. Los que se dejaron sentir en la comarca de la forma que he explicado afectaron, aunque más atenuados, a toda la provincia de Almería y las colindantes de Murcia y Granada. La actividad sísmica en el Mediterráneo fue especialmente persistente aquel verano y la prensa del momento transmitía a principios de agosto aterradoras noticias procedentes de Italia, donde las sacudidas no daban tregua a los habitantes de Génova y Forlí, el Etna no había dejado de vomitar lava en las últimas jornadas y "sobre Lombardía -hecho curioso- vense descender con gran frecuencia globos de fuego" 52 . En el otro extremo del planeta, en la colonia española de Filipinas, un sismo de inusual violencia golpeó a cientos de islas de aquel archipiélago, sembrando la destrucción en cientos de pueblos y ciudades y causando la muerte de miles de personas.

\footnotetext{
${ }^{51}$ Ibidem, p. 586.

${ }^{52}$ El Clamor Público, $2^{\text {a }}$ Época, $n^{\circ}$ 912, 9 de agosto de 1863, p. 1.
} 


\section{5.- REFERENCIAS BIBLIOGRÁFICAS.}

Arciniega, J. (1866). Biografía. Revista Minera, tomo XVII, pp. 449-453.

Castro Guisasola, F. (1932). Terremotos en la provincia de Almería, en La Independencia, publicado por entregas entre el 6 de abril y el 14 de junio de 1932.

Fernández Bolea, E. (2003). Un día de San Diego hace 140 años, en Libro de Fiestas de San Diego, Cuevas del Almanzora.

García Asensio, E. (1910). Historia de la villa de Huércal-Overa y su comarca, Murcia, Tipografía de José Antonio Jiménez, Tomo II.

Molina Sánchez, A. (1990). El libro de Cuevas del Almanzora hace un siglo, Almería, Ayuntamiento de Cuevas del Almanzora.

Ochotorena, F. (1977). La vida de una ciudad. Almería. Siglo XIX (1850-1899), Almería, Librería-Editorial Cajal.

Prado, C. (1863a). Los terremotos de la provincia de Almería, por D. Casiano del Prado, individuo de la Sociedad Meteorológica de Francia, etc. (I). Revista Minera, tomo XIV, 1863.

Prado, C. (1863b). Terremotos en la provincia de Almería”, en Escenas Contemporáneas, Madrid, Imprenta del Colegio de Sordo Mudos y de Ciegos, Tomo I, pp. 385-386.
Publicaciones periódicas:

- El Clamor Público

- Escenas Contemporáneas

- Galicia: revista universal de este reino

- La Concordia. Revista Moral, Política y Literaria

- La Esperanza

- La Iberia

- La Independencia

- Revista Minera

Fuentes archivísticas:

- Archivo Municipal de Cuevas del Almanzora

- Archivo Municipal de Vera

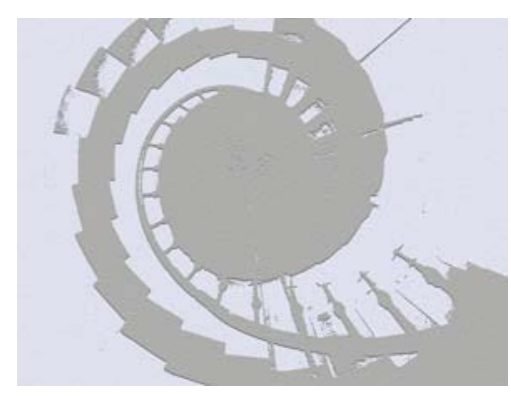

